\title{
ARTICLE
}

\section{Examining the impact of emotional and behavioral problems on parenting stress in mothers of children with autism in Mongolia}

\author{
Bulganzaya Tumurbaatar $^{1 *}$ and Baigalmaa Chuluunbaatar ${ }^{2}$ \\ ${ }^{1}$ Social Work Department, Mongolian National University of Education, \\ Ulaanbaatar, Mongolia. \\ ${ }^{2}$ Special Education Department, Mongolian National University of Education, \\ Ulaanbaatar, Mongolia.
}

ARTICLE INFO: Received: 28 Apr, 2020; Accepted: 08 Sep, 2020

\begin{abstract}
The present study examined the effects of emotional and behavioral problems on parenting stress among mothers of children with autism in Mongolia. The hypothesis is that if children with autism presented more problems on their emotional and behavioral aspects, the higher parenting stress perceived among the mother of children with autism. The convenience sample of the study was composed of 62 mothers of children with autism spectrum disorder. The present study used the Parenting Stress Index-Short form (PSI/SF) and the Strengths and Difficulties Questionnaire (SDQ), which are translated into Mongolian language by research team. Using the current sample of mothers of children with autism, Cronbach's alpha coefficients of PSI/SF-M was 0.94 and SDQ-M was 0.62 for our sample. Bivariate correlation between the variables measuring difficulties of child and parenting stress revealed the existence of small to moderate correlations between $S D Q$ subscales and PSI/SF subscales. PSI/SF total score and SDQ total score are correlated significantly at 0.35 $(p=0.01)$. Difficult child subscale is correlated mild to moderate with SDQ total score (0.53), emotional symptoms (0.37), hyperactivity/inattention (0.35) and conduct problem (0.50) in positive way. Strong correlations were found between subscales of PSI/SF (0.67-0.89). The result of multiple regression analysis indicated that in addition with emotional and behavioral problems of children, income sufficiency of household and social support variables is significantly associated with parenting stress of mothers.
\end{abstract}

Keywords: Parenting stress; autism spectrum disorder; emotional and behavioral problem of children and difficult child;

\section{INTRODUCTION}

Autism spectrum disorder is regarded as a complex neurodevelopmental disorder that involves persistent alterations in social interaction, verbal and nonverbal communication and restricted / repetitive behaviors [1].

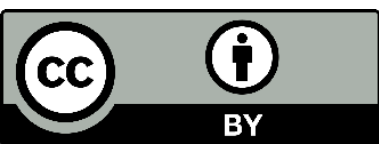

The Author(s). 2020 Open access This article is distributed under the terms of the Creative Commons Attribution 4.0 International License (https://creativecommons.org/licenses/by/4.0/), which permits unrestricted use, distribution, and reproduction in any medium, provided you give appropriate credit to the original author(s) and the source, provide a link to the Creative Commons license, and indicate if changes were made. 
It is one of that disorders that spread fast among the population worldwide in the past decades. Its prevalence is 1 in 54 children in the United States, according to estimates from the Center for Disease Control and Prevention [2]. In Mongolia, the prevalence of children with autism among population is unknown. There is no officially estimated number about the prevalence of children and adults with autism spectrum disorder among the population in Mongolia. Registered number of children and people with autism, according to the Autism Association of Mongolia, organizations working on this issue, including Public Mental Health Institution, are approximately 763 as of 2019.

Parents of children with autism spectrum disorder experience multiple challenges and are overwhelmed by higher level of stress as compared to parents with typically normal children [3]. Parents raising a child with chronic disability are frequently affected with stress, which is caused by changes in their married life, career and social relationship [4]. Studies show that families raising a child with disability experience higher financial burden than families with typical children [5]. Financial burden contributes greatly to the stress and affects negatively the well-being of parents and children as well.

Taking care of children with autism demands continuous and long-term responsibility from the parents. If there is limited or no social support, parents struggle to find a job and maintain it. Employment of the parents not only supports the family's livelihood and treatment cost for child, but also affects the well-being of parents by taking them out of social network. Research evidence showed that working mothers of children with disability are unable to fully meet the demands of the workplace [6]. Balancing work and

\section{MATERIALS AND METHODS}

\section{Participants}

A cross sectional survey was conducted from January to March 2020 in Mongolia. Convenience sample of the study composed of 62 mothers of children with autism spectrum disorder. Mothers were included in the study family related responsibilities requires enormous effort from the mothers, which negatively contributes to their stress. Consequently, most of the mothers taking care of their children with such disabilities are unemployed and stay at home depending solely on their spouse's salary and the limited amount of social welfare benefits accorded to their children.

Emotional and behavioral problems, including hyperactivity, inattention, emotional symptoms and conduct problems are commonly observed in children with autism. Study shows that higher parenting stress among mothers is caused by more behavioral and emotional problems presented by their children with disability [7-9]. Children with autism often have difficulty conforming to social expectations and present unpredictable and inappropriate behaviors in communicating with people and using the objects in public. Parents have faced discriminating attitudes from people responding negatively to such unusual behaviors of their children with chronic disability [10]. Faced with such stigmatization, parents tend to keep to themselves, isolating themselves from many aspects of society [11]. Accumulated parenting stress can cause negative psychological functioning and poor wellbeing of parents as well [12].

The present study examined the effects of emotional and behavioral problems on parenting stress among mothers of children with autism in Mongolia. The hypothesis is that if children with autism presented more problem on their emotional and behavioral aspects, the higher parenting stress was perceived among mothers of children with autism. The results of the study will hopefully contribute to developing stress prevention mechanisms and coping interventions for parents of children with autism in Mongolia.

sample if they had a child between the age of 2 and 10 with a diagnosis of autistic spectrum disorder made by specialists of the National Mental Health Center in Mongolia or other organization which supported the diagnosis for children with autism. Mothers were contacted 
through special education kindergartens, schools and non-governmental organizations authorized to provide educational services for parents of children with autism.

\section{Measures}

Three measures were included in this study. Mother's personal demographics (age and gender), socio-economic status (education and employment status,), and child's characteristics (age and gender, diagnosis, enrollment in educational institutions, and household variables (household income per family member and level of livelihood of household, additional help engaged for caregiving) were included in the demographic screening form. The remaining measures are described below.

\section{Parenting Stress Index Short Form (PSI/SF; Abidin 1992)}

The present study used the translated version of the PSI/SF, which has been translated into Mongolian by the research team. The PSI/SF is a 36-item self-administered form to rapidly assess parenting stress based on three subscales of parental distress (PD), parent-child dysfunctional interaction (PCDI) and difficult child (DC) [13]. Participants had to respond to each item according to a 5-point Likert Scale ranging from 1 (strongly disagree) to 5 (strongly agree). Each subscale generates a stress score and total score is computed from the three subscales. A higher score on subscale and total score represents a greater level of stress perceived by respondents. The primary interpretative framework of the PSI/SF is percentile based. Each subscale and total stress score have a cut-off point, which are calculated based on table to convert raw scores to percentiles, above which a significant level of parenting stress is indicated.

Cronbach alpha reliability coefficients were found to be approximately 0.90 . (As per test-retest coefficients, the total number of parental distress (PD) summary index is 0.78 and as per each sub-scale, the PD coefficient is 0.84 , parent-child dysfunctional interaction (PCDI) coefficient is 0.85 and difficult child (DC) coefficient is 0.68 .)
Strengths and Difficulties Questionnaire (SDQ) The Strengths and Difficulties Questionnaire is an instrument composed of 25 items, which is used to assess the emotional problems, behavioral problems and strengths of children aged between 2 and 16 years [14]. The 25 items in the SDQ compromise of five subscales of 5 items each, with four subscales assessing the difficulties (emotional symptoms, hyperactivity/inattention, conduct problems and peer problems), and one subscale assessing the strength (prosocial behavior). Each 25 item is rated from 0 (not true), 1 (somewhat true) to 2 (certainly true). Subscale score is computed from the scores of corresponding items. Two cut-off points were used in each subscale to distinguish children into three different levels: close to average, at risk and at high risk. Higher subscale scores represent a higher level of emotional and behavioral problems in difficulties subscales. For strengths subscale, lower subscale scores represent problem in prosocial behavior of child. In our study, the total score for difficulties was used for the analysis, with a Cronbach`s alpha 0.62 for our sample.

\section{Social support scale}

Social Functional Support Questionnaire Duke-UNC (Broadhead et al., 1988; adaptation to the Spanish population by Bellyn Saameco et al., 1996) is an instrument to rate perceived support by 14 items, using a five-point Likerttype response scale (from 1 point "much less than what I would like" to 5 points "as much as I like") from participants. The direct score on instrument were used to determine the level of social support [15]. Cronbach`s alpha was 0.92 for our sample indicating good internal consistency.

\section{Procedure}

This study is funded by the MNUE small grant program for science in Mongolia. Cover letters and informed consent form were distributed to mothers of children with autism. Participants who agreed to participate had to fill out three questionnaires, including demographic screening form, PSI-SF and SDQ. 


\section{Data analysis}

Data were analyzed with the SPSS for windows, version 24 [16]. Pearson correlations were calculated to examine the relationship between emotional and behavioral difficulties

\section{RESULTS AND DISCUSSION}

\section{Demographic characteristics of participants}

A total of 62 mothers took part in the study. The mean age of mothers was 33.6 years $(\mathrm{SD}=5.0)$ and the mean age of children was 5.61 $(\mathrm{SD}=1.9)$. Majority of mothers were aged between 25 and 39. 9.7 percent of all participating mothers were divorced and the of children and parenting stress of mothers. A multiple regression analysis was used to study the impact of the variables of emotional and behavioral difficulties symptoms in SDQ to the parenting stress index

remaining 87.1 percent were married. In terms of educational background, 95.2 percent were educated at university level or above. Unemployed mothers accounted for 25.8 percent of the study participants. Table 1 shows the demographic characteristics of mothers of children with autism.

Table 1. Socio-demographic characteristics of mothers

\begin{tabular}{|c|c|c|c|}
\hline \multicolumn{2}{|r|}{$\begin{array}{c}\begin{array}{l}\text { Socio-demographic characteristics of } \\
\text { mothers }\end{array} \\
\text { ? }\end{array}$} & Number & Percent \\
\hline \multicolumn{4}{|c|}{ Age distribution } \\
\hline 1. & $25-29$ & 14 & 22.6 \\
\hline 2. & $30-34$ & 20 & 32.3 \\
\hline 3. & $35-39$ & 22 & 35.5 \\
\hline 4. & $40-44$ & 5 & 8.1 \\
\hline 5. & Above 45 & 1 & 1.6 \\
\hline \multicolumn{4}{|c|}{ Marriage status } \\
\hline 1. & Married & 54 & 87.1 \\
\hline 2. & Divorced & 6 & 9.7 \\
\hline 3. & Separated & 1 & 1.6 \\
\hline 4. & Other & 1 & 1.6 \\
\hline \multicolumn{4}{|c|}{ Education } \\
\hline 1. & Secondary/vocational & 3 & 4.8 \\
\hline 2. & University/postgraduate & 59 & 95.2 \\
\hline \multicolumn{4}{|c|}{ Employment } \\
\hline 1. & Employer & 26 & 41.9 \\
\hline 2. & Self-employed & 9 & 14.5 \\
\hline 3. & Studying & 2 & 3.2 \\
\hline 4. & Unemployed & 16 & 25.8 \\
\hline 5. & Employee & 2 & 3.2 \\
\hline 6. & Other & 7 & 11.3 \\
\hline \multicolumn{4}{|c|}{ Number of children with autism } \\
\hline 1. & 1 child with autism & 58 & 93.5 \\
\hline 2. & 2 children with autism & 4 & 6.5 \\
\hline
\end{tabular}

Most of the children with autism covered in this study are male (74.2). 25.8 percent of the children diagnosed were in the age bracket of 1 to $2,69.4$ percent of the children diagnosed were 3-5 years old. Almost one half of the children were older than their siblings.

See table 2. 
Table 2. Demographic characteristics of children with autism

\begin{tabular}{|l|l|c|c|}
\hline \multicolumn{2}{|l|}{ Socio-demographic characteristics of child } & Number & Percent \\
\hline \multicolumn{2}{|l|}{ Gender of children } & & \\
\hline 1. & Female & 16 & 25.8 \\
\hline 2. & Male & 46 & 74.2 \\
\hline Order of child & 9 & \\
\hline 1. & Single child of family & 30 & 14.5 \\
\hline 2. & Oldest child & 12 & 48.4 \\
\hline 3. & Middle child & 11 & 19.3 \\
\hline 4. & Youngest child & & 17.7 \\
\hline Age range diagnosed with autism & 16 & \\
\hline 1. & Between age of 1 and 2 & 43 & 25.8 \\
\hline 2. & Between age of 3 and 5 & 2 & 69.4 \\
\hline 3. & Between age of 6 and 7 & 3.2 \\
\hline
\end{tabular}

The main caregiver of a children with autism is the mother in the study. 45.2 percent of such mothers were taking care to their children mainly by herself, 48.4 percent of them received help from the father for children's care. In response to question as to whom mothers mostly consult about their children, the answer was mainly husband (29.8), other parents of children with autism $(28,2)$ and professionals, including doctors, psychologists and specialists on disability (17.6).

\section{Problems perceived by mothers of children with autism}

Mothers of children with autism are more likely to perceive themselves as being stigmatized in relation with contradiction between the normal appearance of the child and severity of emotional and conduct problems of their childreb (12). In order to clarify the challenges and difficulties perceived by mothers in relation with taking care of children with autism, multiple response questions were asked. The most responded options of mothers regarding the problems are "lack of understanding among people about children with autism" (75.8) and "negative attitude and discrimination of people toward children with autism" (66.1). This shows that that the understanding about children with autism among the public is low in Mongolia, which is why mothers of children with autism perceive themselves as stigmatized.

The other challenging problem mothers with autistic children encounter is the employment issue. Almost 1 in 2 mothers have experienced the problem of "being unable to work due to the need to take care their children". Due to the increasing need to take care of disruptive nature of behaviors associated with autism of their children, mothers are unable to be employed for a fulltime job.

More detailed information about response rate on perceived problems of mother are showed in Figure 1. 


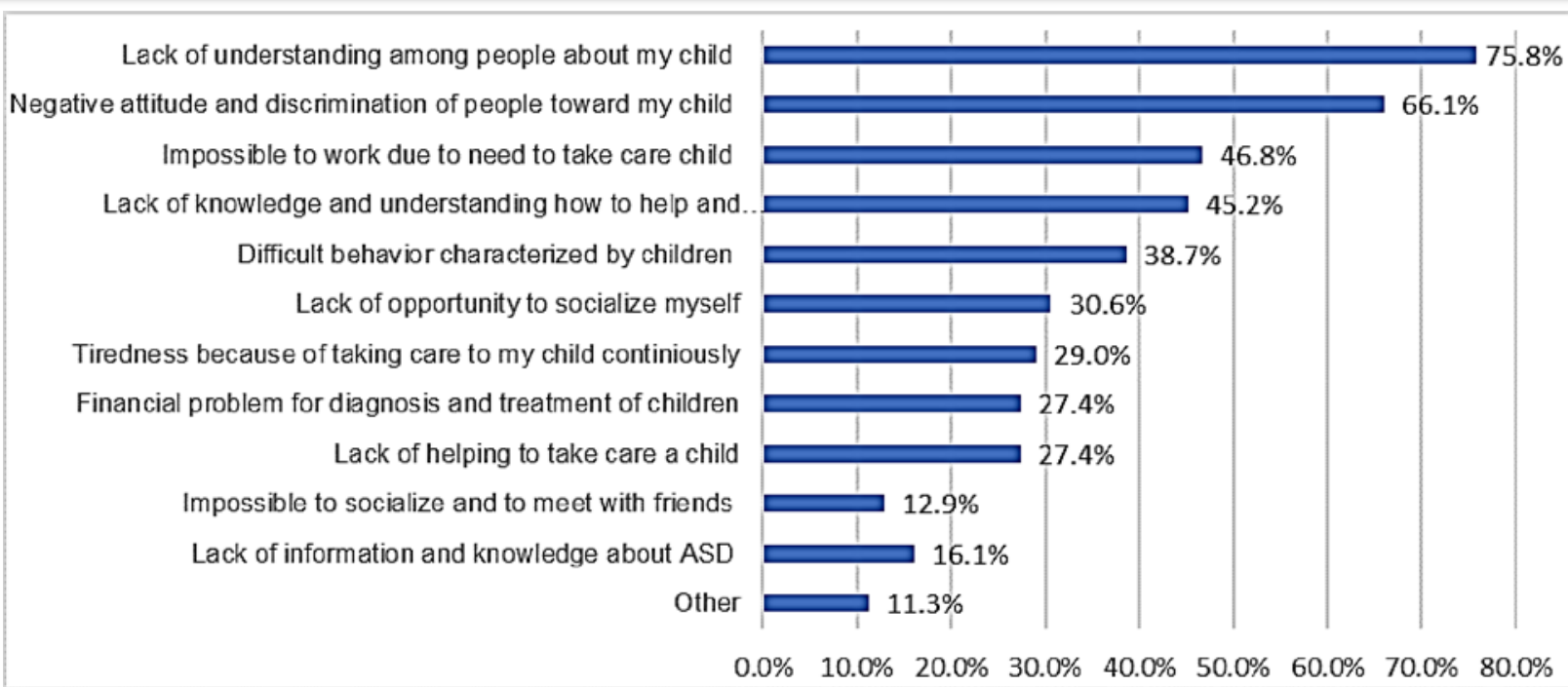

Figure 1. Perceived problems of mothers of children with autism

The question on self-perceived household income sufficiency was asked from participant mothers in this study. 28 percent of mothers were of the view that the income was just enough to get by, 40.3 percent of mothers said their income sufficiency as average, while another 30 percent of them stated that they were struggling to meet their needs by the household income per person.
Impact of behavioral problem of children with autism on parents' stress of mothers

Descriptive statistics of PSI/SF (parenting stress index short form) and SDQ (strength and difficulties questionnaire) were shown in Table 3. Mean scores are displayed in accordance with subscales of the instruments.

Table 3. Descriptive statistics of PSI/SF (Parenting stress index short form) and $S D Q$ (Strength and Difficult questionnaire)

\begin{tabular}{|l|l|c|c|c|c|}
\hline \multicolumn{2}{|l|}{} & Mean & SD & Minimum & Maximum \\
\hline \multicolumn{2}{|l|}{ PSI/SF total } & 112.06 & 24.59 & 59 & 173 \\
\hline & Parental distress & 35.95 & 9.96 & 19 & 58 \\
\hline & Parent-child dysfunctional interaction & 34.34 & 9.10 & 14 & 57 \\
\hline \multicolumn{2}{|l|}{ Difficult child } & 41.77 & 8.71 & 25 & 60 \\
\hline \multicolumn{2}{|l|}{ SDQ total } & 18.69 & 4.85 & 7 & 28.00 \\
\hline & Prosocial scale & 3.51 & 2.59 & .00 & 10.00 \\
\hline & Peer problem scale & 6.12 & 1.88 & 3.00 & 10.00 \\
\hline & Conduct problem scale & 2.70 & 1.45 & .00 & 6.00 \\
\hline & Emotional symptoms scale & 3.03 & 2.04 & .00 & 10.00 \\
\hline & Hyperactivity scale & 6.82 & 2.32 & .00 & 10.00 \\
\hline
\end{tabular}

Among the three domains of PSI/SF, difficult child domain's mean score is the highest (41.77) (table 3). 62.9 percent of mothers scored as clinically significant in difficult child domain, indicating that higher parenting stress is caused by the child's difficult behavior (Fig. 2). This finding indicated that difficult child was the most stressful domain for mothers of children with autism. 


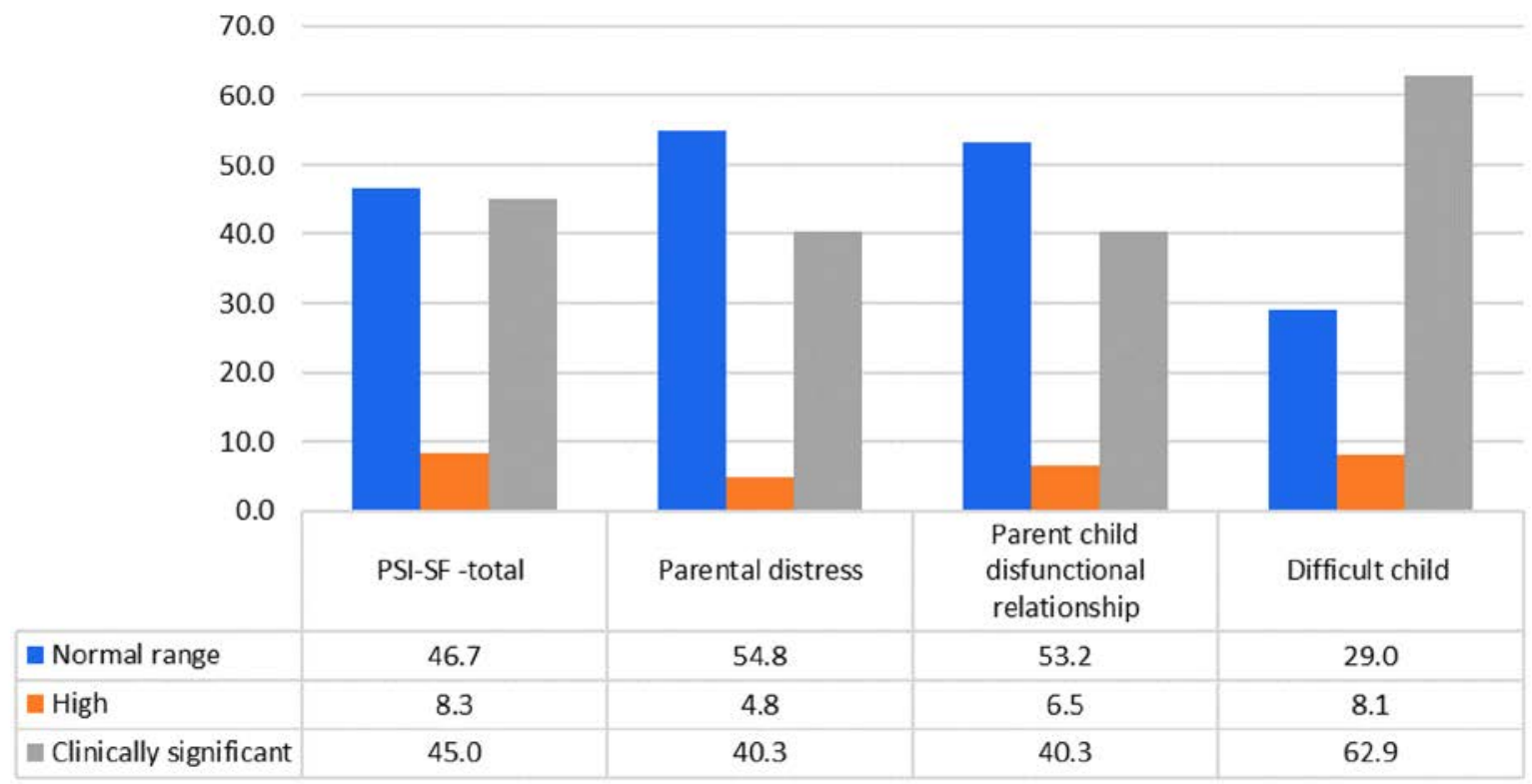

Figure 2. Group distribution of the subscales of PSI/SF

As for the difficulties of behavior problems measured by SDQ, distribution of percentage are 12.9 percent $(n=8)$ close to average, 21 percent at risk and 66.1 percent at high risk. Comparison of the mean scores among four subscales assessing difficulties in the SDQ revealed higher mean scores in the domains of hyperactivity/inattention (6.8) and peer problems (6.1) (see Table 3). Furthermore, most children were characterized as at high risk of having problems for peer problems, hyperactivity/inattention and prosocial behavior. (Fig.3).

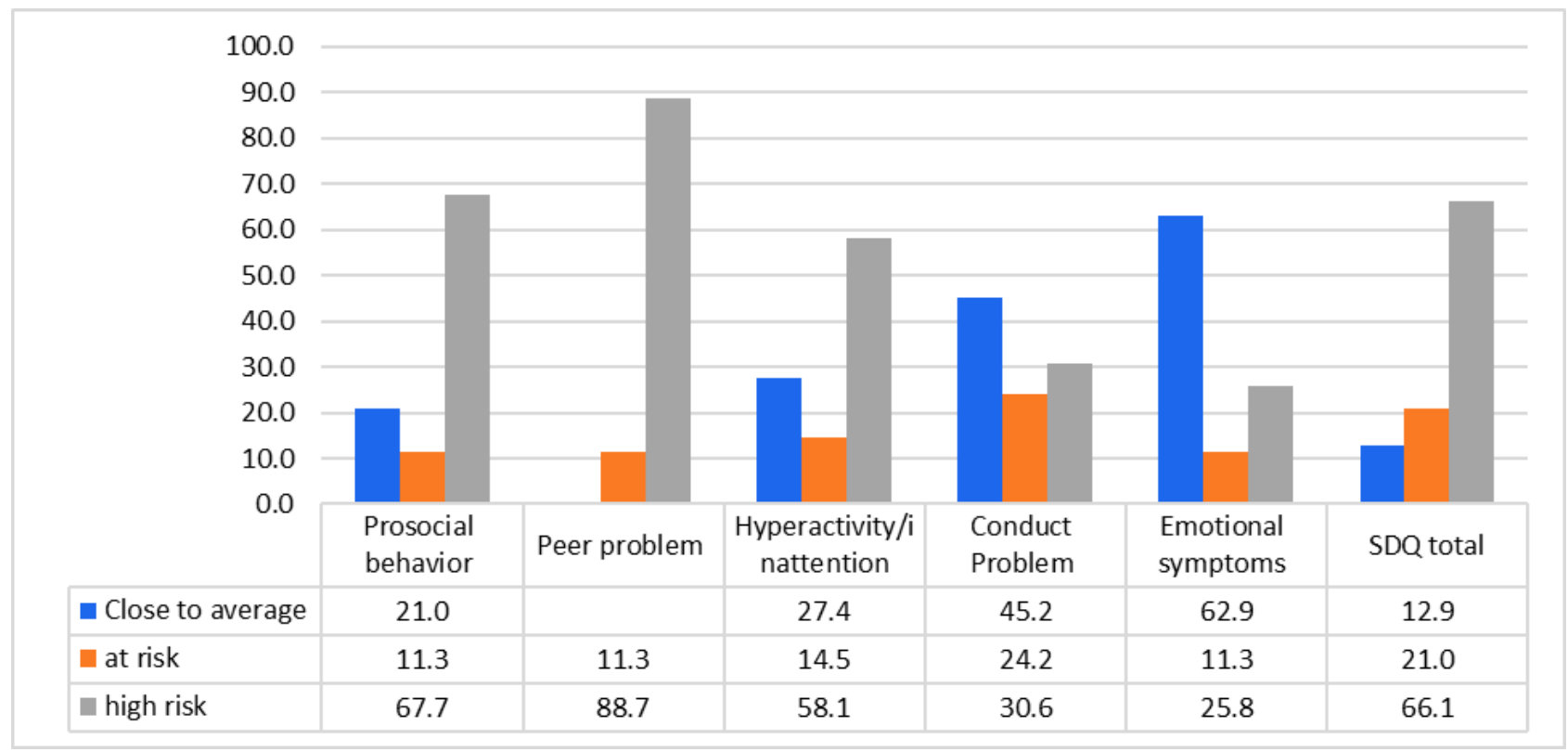

Figure 3. Group distribution of subscales of SDQ (Strength and Difficulties Questionnaire)

Regression analysis was conducted to examine if a child's behavioral problems were related to parenting stress. The result indicated that there is a significant association $(\beta=0.35$, $\mathrm{p}=.000)$ between total score of SDQ and $\mathrm{PSI} / \mathrm{SF}$ total score (Table 4). 
Table 4. Model Summary of regression analysis of total score of SDQ (Strength and difficulties questionnaire) on parenting stress of participants

\begin{tabular}{|c|c|c|c|c|}
\hline Model & $\mathrm{R}$ & R Square & Adjusted R Square & $\begin{array}{c}\text { Std. Error of the } \\
\text { Estimate }\end{array}$ \\
\hline 1 & $.355^{\mathrm{a}}$ & .126 & .119 & 22.16061 \\
\hline
\end{tabular}

a. Predictors: (Constant), Total score of SDQ

ANOVA ${ }^{\mathrm{a}}$

\begin{tabular}{|c|l|c|c|c|c|c|}
\hline \multicolumn{2}{|l|}{ Model } & Sum of Squares & df & Mean Square & F & Sig. \\
\hline \multirow{3}{*}{1} & Regression & 8629.544 & 1 & 8629.544 & 17.572 & $.000^{\mathrm{b}}$ \\
\cline { 2 - 8 } & Residual & 59913.295 & 122 & 491.093 & & \\
& Total & 68542.839 & 123 & & & \\
\end{tabular}

a. Dependent Variable: PSI_SUM

b. Predictors: (Constant), SDQ_SUM

\begin{tabular}{|c|c|c|c|c|c|c|}
\hline \multicolumn{7}{|c|}{ Coefficient $^{\mathrm{a}}$} \\
\hline \multirow{2}{*}{\multicolumn{2}{|c|}{ Model }} & \multicolumn{2}{|c|}{ Unstandardized Coefficients } & Standardized & \multirow{2}{*}{$\mathrm{t}$} & \multirow{2}{*}{ Sig. } \\
\hline & & $\mathrm{B}$ & Std. Error & Beta & & \\
\hline \multirow[b]{2}{*}{1} & (Constant) & 78.746 & 7.925 & & 9.936 & .000 \\
\hline & $\begin{array}{l}\text { Total score } \\
\text { of SDQ }\end{array}$ & 1.722 & .411 & .355 & 4.192 & .000 \\
\hline
\end{tabular}

a. Dependent Variable: PSI_SUM

Multiple regression analysis was conducted to explore the impact of demographic variables of mother and children, and social support level on parenting stress of mothers. The results of the multiple regression analysis indicated that the significant predictors that explained highest percentage of variance in parenting stress were the total score of Strength and Difficulties Questionnaire $(\beta=0.26, \mathrm{p}$ $=.003)$, total score social support $(\beta=-0.27$, $\mathrm{p}=0.002)$ and income sufficiency of household $(\beta=-0.25, p=0.003)$. Variables on child and mother's age, mother's education and employment status and father's involvement in child care were not significantly associated with parenting stress of participants.

Table 5. Model Summary of multiple regression analysis of total score of SDQ (Strength and Difficulties Questionnaire), social support and demographic variables on parenting stress of participants

\begin{tabular}{|c|c|c|c|c|}
\hline Model & $\mathrm{R}$ & R Square & $\begin{array}{c}\text { Adjusted R } \\
\text { Square }\end{array}$ & Std. Error of the Estimate \\
\hline 1 & $.574^{\mathrm{a}}$ & .329 & .281 & 20.16440 \\
\hline
\end{tabular}

a. Predictors: (Constant), Mother's age, Mother's educational level, Mother's employment, Income sufficiency of household, Total score of SDQ, Child age, level of social support

\begin{tabular}{|c|c|c|c|c|c|c|}
\hline \multicolumn{7}{|c|}{ ANOVA $^{\mathbf{a}}$} \\
\hline Model & & Sum of Squares & $\mathrm{df}$ & Mean Square & $\mathrm{F}$ & Sig. \\
\hline \multirow{3}{*}{1} & Regression & 22521.119 & 8 & 2815.140 & 6.924 & $.000^{\mathrm{b}}$ \\
\hline & Residual & 45946.160 & 113 & 406.603 & & \\
\hline & Total & 68467.279 & 121 & & & \\
\hline
\end{tabular}

a. Dependent Variable: Total score of Parenting Stress Index

b. Predictors: (Constant), Mother's age, Mother's educational level, Mother's employment, Income sufficiency of household, Total score of SDQ, Child age, level of social support

Coefficients $^{\mathbf{a}}$

\begin{tabular}{|c|c|c|c|c|c|c|}
\hline \multirow{2}{*}{\multicolumn{2}{|c|}{ Model }} & \multicolumn{2}{|c|}{ Unstandardized Coefficients } & \multirow{2}{*}{$\begin{array}{c}\text { Standardized } \\
\text { Coefficients }\end{array}$} & \multirow[t]{2}{*}{$\mathrm{t}$} & \multirow[t]{2}{*}{ Sig. } \\
\hline & & $\mathrm{B}$ & Std. Error & & & \\
\hline \multirow{5}{*}{1} & (Constant) & 132.090 & 20.262 & & 6.519 & .000 \\
\hline & Total score of SDQ & 1.289 & .426 & .260 & 3.028 & .003 \\
\hline & Total score Social Support & -.651 & .206 & -.279 & -3.165 & .002 \\
\hline & Mother's age & -.215 & .379 & -.045 & -.568 & .571 \\
\hline & Child age (month) & 1.002 & 1.073 & .079 & .934 & .353 \\
\hline
\end{tabular}




\begin{tabular}{|c|c|c|c|c|c|}
\hline $\begin{array}{l}\text { Income sufficiency of } \\
\text { household }\end{array}$ & -6.273 & 2.067 & -.256 & -3.035 & .003 \\
\hline Mother's educational level & -.851 & 8.912 & -.008 & -.096 & .924 \\
\hline Mother's employment & -.190 & 4.428 & -.003 & -.043 & .966 \\
\hline $\begin{array}{l}\text { Father's involvement in } \\
\text { child care }\end{array}$ & -.348 & 3.824 & -.007 & -.091 & .928 \\
\hline
\end{tabular}

a. Dependent Variable: Total score of PSI/SF

Bivariate correlation between the variables measuring difficulties of child and parenting stress are shown in Table 6. The result revealed the existence of mild to moderate correlation between SDQ subscales and PSI/SF subscales. PSI/SF total score and SDQ total score are mildly correlated at 0.35 $(p<0.01)$. Difficult child subscale is mild to moderate with SDQ total score (0.53), emotional symptoms

(0.37), hyperactivity/inattention $(0.35)$ and conduct problem (0.50) except peer problem. Among the subscales of SDQ, conduct problem is significantly correlated with PSI/SF total $(0.36)$ and difficult child (0.50).

Internal consistence of subscales of $\mathrm{PSI} / \mathrm{SF}$ are between 0.67 and 0.89 indicating good fit.

Table 6. Pearson correlation between PSI/SF total, subscales, SDQ total and domains

\begin{tabular}{|l|c|c|c|c|c|c|c|c|c|}
\hline & 2 & 3 & 4 & 5 & 6 & 7 & 8 & 9 & 10 \\
\hline (1) PSI/SF total & $.879^{* *}$ & $.897^{* *}$ & $.880^{* *}$ & $.370^{* *}$ & $.279^{*}$ & $.252^{*}$ & $.366^{* *}$ & .052 & -.193 \\
\hline (2) Parental distress & 1 & $.670^{* *}$ & $.639^{* *}$ & .213 & .153 & .172 & .244 & -.014 & -.078 \\
\hline $\begin{array}{l}\text { (3) Parent-child } \\
\text { dysfunctional interaction }\end{array}$ & & 1 & $.721^{* *}$ & $.259^{*}$ & .225 & .156 & .241 & .035 & -.151 \\
\hline (4) Difficult child & & & 1 & $.530^{* *}$ & $.379^{* *}$ & $.352^{* *}$ & $.502^{* *}$ & .128 & $-.297^{*}$ \\
\hline (5) SDQ total & & & & 1 & $.649^{* *}$ & $.693^{* *}$ & $.575^{* *}$ & $.579^{* *}$ & $-.305^{*}$ \\
\hline $\begin{array}{l}\text { (6) Hyperactivity } \\
\text { inattention }\end{array}$ & & & & & 1 & .166 & $.314^{*}$ & .013 & -.137 \\
\hline (7) Emotional symptoms & & & & & & 1 & .185 & $.351^{* *}$ & -.111 \\
\hline (8) Conduct problem & & & & & & & 1 & .122 & $-.351^{* *}$ \\
\hline (9) Peer problems & & & & & & & & 1 & -.225 \\
\hline (10) Prosocial behavior & & & & & & & & & 1 \\
\hline
\end{tabular}

**. Correlation is significant at the 0.01 level (2-tailed)

*. Correlation is significant at the 0.05 level (2-tailed).

This study examined the impact of emotional and behavioral problems of children with autism on parenting stress in mothers of children with autism. The results indicated that mothers of children with autism perceived higher stress in difficult child domain than other two domains, such as parental distress and parent-child dysfunctional interaction of parenting stress index. Difficult child domain in parenting stress is associated with difficulties of emotional and behavioral problems of children, including emotional symptoms, hyperactivity/inattention and conduct problem in accordance with the correlation and regression analysis in this study. It can be concluded that emotional and behavioral difficulties of children with autism is one factor that contributes to the mother's parenting stress, based on results of regression and correlation analysis. The impact of demographic variables, including educational and employment status, father's involvement in child care are not significant on the parenting stress of mothers. The income sufficiency of household is stated as significant association with parenting stress. If income sufficiency is not enough to sustain household livelihood, the parenting stress among mothers can be expected to be high. Another variable that significantly contributes to the parenting stress of mother is the social support. It can be assumed that a mother, whose social support is high, the parenting stress is low. 
Notable finding reported in the study is that almost 1 in 4 mothers perceived social problems related with lack of understanding among people about their child and 3 in 5 mothers perceived negative social attitude and discrimination toward their child. As the current study examined the impact of child's emotional and behavioral problems on parenting stress, a possible factor that obviously contributes to the parents' stress can be the social attitude toward children with autism. Further qualitative and quantitative study needs to be conducted in this area.

\section{CONCLUSIONS}

This study found that in Mongolia some emotional and behavioral problems of children with autism spectrum disorder respectively contribute to the parenting stress of mothers of children with autism. Mothers are perceived to have higher stress in relation with difficult behavior of their children, which is caused by emotional symptoms, hyperactivity/inattention and conduct problem of their child rather than peer problem and prosocial behavior.

Study limitations and future consideration

Study findings may not be generalizable to all parents of children with autism due to the small size of the sample. A nationwide study to explore the social and psychological well-being of the children with autism and their parents are recommended in the future.

This study, for the first time in Mongolia, applied widely used instruments in the field of stress among parents with disabled children worldwide. The instruments applied in this study needs to be validated in terms of psychometric properties among the large sample of the population in Mongolia. The results of this study will contribute to developing and revising these instruments to be applied in clinical practice in Mongolia.

Comparative and longitudinal research design needs to be applied in the future in exploring in more depth parent stress in relation to child disability.

Acknowledgements This study is supported by a grant from the Mongolian National University of Education. Special thanks to the Autism Association of Mongolia for the assistance in conducting this study.

172-183.

doi:10.1111/j.13652788.2005.00732.x

4. Gray, D.E. (1993), Perceptions of stigma: the parents of autistic children. Sociology of Health \& Illness, 15: pp. 102-120. doi:10.1111/1467-9566.ep1134380210-

Baker BL, McIntyre LL, Blacher J, Crnic K, Edelbrock C, Low C. (2003). Pre-school children with and without developmental delay: Behavior problems and parenting stress over time. Journal of Intellectual Disability Research 47:217-230.

5. Kuhlthau, K., Hill, K.S., Yucel, R. et al. (2005). Financial Burden for Families of Children with Special Health Care Needs. Matern Child Health J 9, pp. 207-218 https://doi.org/10.1007/s10995-005-4870$\mathrm{X}$ 
6. Parish, S., \& Cloud, J. (2006). Financial Well-Being of Young Children with Disabilities and Their Families. Social Work, 51(3), pp. 223-232. Retrieved April 22, 2020, from www.jstor.org/stable/23721200

7. Hastings, Richard. (2003). Child behavior problems and partner mental health as correlates of stress in mothers and fathers of children with autism. Journal of intellectual disability research: JIDR. 47. 231-7. 10.1046/j.1365-2788.2003.00485. $\mathrm{x}$.

8. Huang, C., Yen, H., Tseng, M. et al. (2014). Impacts of Autistic Behaviors, Emotional and Behavioral Problems on Parenting Stress in Caregivers of Children with Autism. J Autism Dev Disorder 44, pp.

$1383-1390$

https://doi.org/10.1007/s10803-013-2000y

9. Baker BL, McIntyre LL, Blacher J, Crnic K, Edelbrock C, Low C. (2003). Pre-school children with and without developmental delay: Behavior problems and parenting stress over time. Journal of Intellectual Disability Research 47:217-230

10. Courcy, Isabelle \& Riviéres, Catherine. (2017). "From cause to cure": A qualitative study on contemporary forms of mother blaming experienced by mothers of young children with autism spectrum disorder. Journal of Family Social Work. 20. 1-18. 10.1080/10522158.2017.1292184.
11. Gill, Jessica \& Liamputtong, Pranee. (2011). Being the Mother of a Child with Asperger's Syndrome: Women's Experiences of Stigma. Health care for women international. 32. 708-22. 10.1080/07399332.2011.555830.

12. Peterson, J., \& Hawley, D. (1998). Effects of Stressors on Parenting Attitudes and Family Functioning in a Primary Prevention Program. Family Relations, 47(3), pp. 221-227. doi:10.2307/584970

13. Abidin, R. R. (2012). Parenting Stress index ( $4^{\text {th }}$ ed.).Lutz, FL:PAE

14. Stivanin, L., Scheuer, C. I., \& Assumpção, F. B., Jr. (2008). SDQ (Strengths and Difficulties Questionnaire): Identificação de características comportamentais de crianças leitoras [SDQ (Strengths and Difficulties Questionnaire): Identification of children readers behavioral characteristics]. Psicologia: Teoria e Pesquisa, 24(4), pp. 407-413. https://doi.org/10.1590/S010237722008000400003

15. Broadhead, W. E., Gehlbach, S. H., de Gruy, F. V., and Kaplan, B. (1988). DukeUNC functional social support questionnaire: measurement of social support in family medicine patients. Med. Care 26, 709-723. doi: 10.1097/00005650198807000-00006

16. IBM Corp. (2013). IBM SPSS Statistics for Windows (Version 22.0) [Computer software]. Armonk, NY: Author. 